\title{
RISK ASSESSMENT PADA PEKERJAAN MENEBANG KAYU DI HUTAN PRODUKSI (STUDI KASUS PADA PENGOPERASIAN CHAINSAW PERUM PERHUTANI KPH MADIUN)
}

\author{
Raditya Angga Pradipta \\ Ikatan Alumni Kesehatan Masyarakat Indonesia (IAKMI) Provinsi Jawa Timur \\ Email: raditya.tugas@gmail.com
}

\begin{abstract}
Logging the forest production is a high risk work. The condition of the forest acreage is difficult, the imbalance between the tools used by condition of the field and the skills of workers can lead to accidents. One of supporting job in the process of logging the forest production is the operation of the chainsaw that has hazards and risks which must be controlled. The main objective of this research was to risk assessment in the operational of the chainsaw in the work to cutting down trees in Perhutani KPH Madiun. This research was an observational research that conducted using cross sectional design and descriptive analysis. Data were used primary data based on interviews, observations and secondary data collected from the company. This research performed based on work activities of operating chainsaw. The result showed that based on idetification of hazards in activities of operating chainsaw in cutting trees, there were 18 hazards Risk assessment showed that from 18 pure risks, there were 4 low risks, 7 medium risks and 7 high risks. The conclusion from this research is the risk most dominant obtained from the risk assessment is high risk and risks while each one had the amount of 7 danger or $39 \%$ of all the potential here hazards, to at a job should not be continued, work that needs to be set repeated or attempts to control at work to reduce the risk. Control must be reviewed for conformity before work began.
\end{abstract}

Keywords: cut timber, identification hazards, risk assessment

\begin{abstract}
ABSTRAK
Penebangan hasil hutan produksi merupakan pekerjaan yang berisiko kecelakaan kerja tinggi. Kondisi areal hutan yang sulit, ketidakseimbangan antara alat yang digunakan dengan kondisi lapangan dan keterampilan pekerja dapat menyebabkan kecelakaan kerja. Salah satu pekerjaan yang mendukung dalam proses penebangan hasil hutan produksi adalah pengoperasian gergaji rantai (chainsaw) yang memiliki bahaya dan risiko yang harus dikendalikan. Tujuan penelitian ini adalah untuk melakukan risk assessment pekerjaan pengoperasian chainsaw pada pekerjaan menebang pohon di Perum Perhutani KPH Madiun. Penelitian ini dilaksanakan secara observasional dengan rancangan cross sectional dan dianalisis secara deskriptif. Data yang digunakan adalah data primer dari hasil wawancara dan observasi serta data sekunder yang berasal dari perusahaan. Penelitian dilaksanakan berdasarkan aktivitas dalam pengoperasian chainsaw. Hasil penelitian menunjukkan bahwa dari identifikasi bahaya berdasarkan pekerjaan menebang pohon dengan pengoperasian chainsaw ditemukan 18 bahaya. Berdasarkan penilaian risiko yang dilakukan dari 18 risiko murni terdapat 4 risiko rendah, 7 risiko sedang dan 7 risiko tinggi. Kesimpulan dari penelitian ini adalah Risiko yang paling dominan yang didapat dari hasil risk assessment adalah risiko tinggi dan risiko sedang yang masing-masing mempunyai jumlah 7 bahaya atau $39 \%$ dari seluruh potensi bahaya yang ada, untuk itu pekerjaan tidak boleh dilanjutkan, pekerjaan harus ditetapkan ulang atau dilakukan upaya pengendalian di tempat kerja untuk mengurangi risiko. Pengendalian harus ditinjau ulang untuk kesesuaian sebelum pekerjaan dimulai.
\end{abstract}

Kata kunci: menebang kayu, identifikasi bahaya, penilaian risiko

\section{PENDAHULUAN}

Kegiatan pemanenan hutan dipengaruhi oleh kombinasi beberapa faktor yang saling berkaitan satu dengan yang lain. Ketimpangan oleh salah satu faktor dapat menyebabkan risiko yang berbahaya dan akhirnya dapat menyebabkan kecelakaan. Faktor yang saling berhubungan tersebut adalah manusia, peralatan dan lingkungan kerja, manusia sebagai salah satu faktor penggeraknya merupakan satu- satunya faktor hidup yang sangat rentan dengan bahaya kecelakaan.

Pemanenan kayu merupakan serangkaian kegiatan kehutanan yang mengubah pohon menjadi bentuk yang dapat dipindahkan ke lokasi lain sehingga bermanfaat bagi kehidupan ekonomi dan kebudayaan masyarakat (Suparto, 1999). Kegiatan pemanenan kayu merupakan salah satu kegiatan yang cukup berat dan banyak menimbulkan risiko 
kecelakaan kerja. Keselamatan dan kesehatan kerja dianggap penting dalam sektor kehutanan karena pengelolaan hutan termasuk dalam kategori kegiatan berisiko tinggi. Hal tersebut ditunjukkan Gani (1992) dengan data kecelakaan kerja pada kegiatan kehutanan 4 kali lebih besar dibandingkan angka kecelakaan pada industri lain.

Kegiatan tersebut terdapat beberapa tahapan yaitu penebangan (felling), penyaradan (skidding or yarding), pembagian batang (cutting), pengangkutan (transportation) dan penimbunan kayu (unloading). Berdasarkan peralatan yang digunakan dalam penebangan terdapat 2 sistem yaitu sistem manual dan mekanis. Sistem penebangan manual menggunakan peralatan sederhana seperti gergaji tangan, kapak dan baji, sedangkan kegiatan penebangan secara mekanis menggunakan gergaji rantai (chainsaw). Gergaji rantai dapat digolongkan menjadi 2 jenis utama yaitu gergaji rantai untuk 2 orang (two menchainsaw) dan gergaji rantai untuk 1 orang (one man chainsaw) (Staaf \& Wiksten, 1984). Semakin majunya teknologi pemanenan hasil hutan, manusia mencari jalan untuk membuat alat-alat pemanenan yang semakin sempurna dan memudahkan dalam pekerjaan pemanenan salah satunya adalah penggunaan chainsaw.

Chainsaw (gergaji rantai) adalah gergaji yang menggunakan mesin untuk menggerakkan rantai gergajinya. Pada awalnya orang menebang atau memotong kayu dengan gergaji manual. Setelah mesin ditemukan maka mesin diaplikasikan pada gergaji untuk mendapatkan produktivitas yang tinggi. Chainsaw pada awal pembuatan adalah chainsaw yang lebih besar dan berat (lebih dari 60 $\mathrm{kg}$ ) bahkan dioperasikan secara stasioner oleh lebih dari satu orang operator. Pada saat ini chainsaw sudah mengalami puluhan modifikasi bentuk dan aplikasi teknologi baru sehingga lahirlah chainsaw dengan teknologi mutakhir berupa chainsaw lebih kecil dan lebih ringan serta putaran mesin yang sangat cepat $(>15 \mathrm{rpm})$. Beberapa merk chainsaw terbaru tidak menggunakan engine berbahan bakar minyak tetapi menggunakan tenaga listrik. Chainsaw terbaru juga dilengkapi dengan pengaman atau penangkap rantai, rem rantai, anti vibrasi, serta pelumasan otomatis. Teknologi bahan pada bilah (guide bar) semakin berkembang sehingga diaplikasi bilah yang lebih ringan tetapi tahan terhadap gesekan, tekanan dan panas. Semua hal ini dimaksudkan untuk memberikan kenyamanan dan keselamatan kerja bagi operator chainsaw sekaligus meningkatkan produktivitas kerjanya. (Matangaran, 2007).
Menurut data dari Jamsostek dalam buku kerja perindustrian Indonesia (ASEAN OSHNET, 2004) menunjukkan bahwa pada sektor kehutanan memiliki risiko kecelakaan ke dua setelah sektor kontruksi yang tinggi dari tahun 1996 didapatkan 16.871 kasus kecelakaan, pada tahun 1997 kasus kecelakaan naik signifikan menjadi 19.561 dan pada tahun 1998 meningkat lagi menjadi 19.640 sedangkan pada tahun 1999 kasus kecelakaan pada sektor kehutanan mengalami penurunan menjadi 16.835 kasus

Pada tahun 1991 Strehlke, seorang spesialis ILO di bidang kehutanan dan industri perkayuan, melakukan kajian terhadap masalah lapangan kerja dan kondisi kerja dalam pekerjaan kehutanan Indonesia. Pada saat itu diperkirakan bahwa jumlah berbagai kategori pekerja kehutanan mencapai sekitar 250 ribu orang. Di semua tempat kerja dijumpai praktik-praktik kerja berbahaya, terutama dalam penebangan pohon. Meskipun buruh-buruh yang bekerja menebang kayu rata-rata memakai helm pelindung kepala, mereka sering kali tidak memakai alas kaki yang memadai. Operator yang menggunakan gergaji rantai/mesin (chainsaw) untuk menebang pohon sering kali bekerja dengan kaki telanjang, tanpa sepatu pelindung. Hal ini berbahaya mengingat gergaji mesin tidak dilengkapi dengan perangkat pelindung seperti untuk pelindung pegangan di bagian depan (front handle guards) atau piranti anti getaran (anti-vibration devices). Kesalahan yang ditimbulkan akibat kelalaian dan ketidaksesuaian tindakan operator dengan ketentuan yang berlaku dapat menimbulkan kecelakaan.

Hasil pengamatan yang dilakukan oleh Suhartana dan Yuniawati pada tahun 2010 di lokasi penelitian daerah tasikmalaya (Kesatuan Pemangku Hutan Tasikmalaya) menunjukkan bahwa pada kegiatan penebangan, operator Chainsaw tidak menggunakan sepatu bot, helm pelindung kepala, sarung tangan dan kaca mata pelindung padahal areal yang dihadapi curam (kelerengan $>25 \%$ ) dan jenis kayu jati yang memiliki kelas kuat I berarti memiliki bobot kayu sangat berat. Hal ini sangat membahayakan keselamatan jiwa operator.

Pencegahan kecelakaan kerja akibat pengoperasian chainsaw pada bidang kehutanan perlu dilakukannya serangkaian kegiatan risk assessment yang mendalam dengan memperhitungkan keadaan lingkungan kerja dan pengendalian yang telah dilakukan. Pelaksanaan hazard identification dan risk assessment dapat mengidentifikasi potensi bahaya yang muncul dan menilai tingkat risiko pada saat pengoperasian chainsaw. Oleh karena itu, pelaksanaan serangkaian 
kegiatan risk assessment sangat penting untuk mengurangi risiko bahaya di tempat kerja, sehingga pekerja merasa aman dan bekerja secara optimal. Penilaian risiko adalah proses mengevaluasi risikorisiko yang diakibatkan adanya bahaya-bahaya dengan memperhatikan kecukupan pengendalian yang dimiliki dan menentukan apakah risikonya dapat diterima atau tidak (OHSAS 18001;2007).

Perum Perhutani KPH Madiun unit hutan produksi merupakan sebuah perusahaan BUMN dalam usaha untuk memanfaatkan hutan produksi yang kegiatannya terdiri dari pemanenan atau penebangan, penanaman, pengamanan, pengolahan dan pemasaran hasil hutan kayu di hutan produksi. Perusahaan ini terletak di kawasan kota Madiun. Wilayah hutan yang dikelola KPH Madiun berdasarkan RPKH Jangka 2011-2020 adalah seluas $31.219,70$ Ha yang terdiri dari 2 kelas perusahaan yaitu kelas perusahaan jati seluas 27.483,60 Ha dan kelas perusahaan kayu putih seluas 3.736,10 Ha. Secara administratif, wilayah KPH Madiun berada pada tiga kabupaten, yaitu Kabupaten Madiun, Ponorogo, dan Magetan. Kawasan hutan KPH Madiun dibagi menjadi 4 bagian hutan yaitu Bagian Hutan Caruban (11.953,60 Ha - KP Jati), Pagotan (4.076 Ha - KP Jati), Ponorogo Barat (6.260,3 Ha - KP Jati), dan Bagian Hutan Ponorogo Timur (5.193,7 Ha -KP Jati dan 3.736,1 Ha - KP Kayu Putih).

Beberapa proses kegiatan hutan produksi yang dilakukan oleh Perum Perhutani KPH Madiun yang terdiri dari penebangan, pembagian batang, pengangkutan dan penimbunan kayu. Kegiatan penebangan kayu menggunakan chainsaw memiliki risiko yang besar terhadap terjadinya kecelakaan kerja. Hal ini disebabkan karena program keselamatan dan kesehatan kerja yang baru terbentuk dan belum berjalan sesuai dengan program yang sudah direncanakan, sehingga dapat menyebabkan risiko terjadi kecelakaan kerja seperti terpotongnya anggota bagian tubuh khususnya tangan dan gangguan kesehatan seperti ketulian akibat suara dari mesin chainsaw dan syndrome hand arm vibration dari getaran yang disebabkan oleh mesin chainsaw.

Tujuan dari penelitian ini adalah melakukan Risk assessment pekerjaan pengoperasian chainsaw pada pekerjaan menebang pohon di Perum Perhutani KPH Madiun mulai dari identifikasi bahaya, melakukan penilaian risiko, penentuan tingkat risiko, dan melakukan evaluasi risiko.

\section{METODE}

Berdasarkan cara pengumpulannya merupakan penelitian observasional, karena dalam penelitian ini hanya mengamati objek penelitian tanpa memberikan perlakuan. Penelitian ini ditinjau dari sistem analisisnya termasuk penelitian deskriptif, yaitu suatu metode penelitian yang dilakukan dengan tujuan utama untuk membuat gambaran tentang suatu keadaan secara objektif. Ditinjau dari segi waktu, rancangan penelitian ini termasuk dalam penelitian cross sectional karena wawancara dan pengamatan terhadap variabel dilakukan serentak dalam periode waktu tertentu.

Objek dari penelitian adalah proses pekerjaan pengoperasian chainsaw yang digunakan pada pekerjaan penebangan kayu pemanenan hasil hutan produksi di Perum Perhutani KPH Madiun. Penelitian ini akan dilakukan dengan mengamati proses pekerjaan pengoperasian chainsaw di tempat kerja sekaligus wawancara dengan 4 (empat) operator chainsaw, serta melakukan wawancara pada 2 (dua) petugas bagian safety.

Lokasi penelitian ini adalah di kawasan hutan produksi Perum Perhutani KPH Madiun yang berada di desa randualas kabupaten madiun. Penelitian ini dilakukan mulai dari bulan agustus 2015 sampai bulan September 2015. Variabel yang diteliti dalam penelitian ini antara lain adalah identifikasi bahaya yang meliputi: bahaya mekanik, bahaya fisis, bahaya ergonomi, bahaya biologi, bahaya listrik dan bahaya kimia yang terdapat pada pekerjaan menebang pohon dan risiko pekerjaan pengoperasian chainsaw pada pekerjaan menebang pohon, kemungkinan kejadian risiko (likelihood) dan tingkat keparahan dampak (severity), dan evaluasi risiko.

Data yang dikumpulkan dalam penelitian ini adalah data sekunder dan data primer. Data sekunder yang dikumpulkan adalah dokumen yang berkaitan dengan program Keselamatan dan Kesehatan Kerja (K3) serta dokumen mengenai pengoperasian chainsaw. Data primer didapatkan dari hasil wawancara dan observasi. Wawancara dilakukan dengan konsep indepth interview pada 5 (enam) narasumber, yaitu 4 orang operator chainsaw, dan seorang petugas bagian safety.

Observasi dilakukan dengan cara pengamatan secara langsung keadaan di tempat kerja untuk menilai bahaya dan risiko serta pengendaliannya pada operator dalam mengoperasikan chain saw yang digunakan dalam menebang pohon hutan produksi. Pengumpulan data dengan observasi menggunakan lembar observasi yang berupa $J o b$ 
Safety Analysis (JSA). Peneliti didampingi oleh petugas bagian Safety pada saat observasi sehingga bukan hanya subjektif peneliti dan observasi dilakukan pada saat pekerjaan dilakukan sehingga pekerja sudah terbiasa dan tidak menimbulkan kecurigaan sehingga sikap pekerja akan tetap alami. Observasi dilakukan dengan mengamati proses dan keadaan secara langsung di tempat kerja untuk melakukan hazard identification, risk assessment, dan risk evaluation yang telah diterapkan pada pekerjaan pengoperasian chainsaw pada pekerjaan menebang pohon. Instrumen yang digunakan dalam mengumpulkan data primer adalah Job Safety Analysis (JSA) yang berisi langkah kerja, bahaya, penilaian risiko dan tingkat risiko. Teknik analisa bahaya ini bermanfaat untuk mengidentifikasi dan menganalisis bahaya dalam suatu pekerjaan (job). Hal ini sejalan dengan pendekatan sebab kecelakaan yang bermula dari adanya kondisi atau tindakan tidak aman saat melakukan suatu aktivitas. Karena itu dengan melakukan identifikasi bahaya pada setiap jenis pekerjaan dapat dilakukan langkah pencegahan yang tepat dan efektif (Ramli, 2010).

Teknik pemeriksaan keabsahan data yang digunakan adalah dengan triangulasi. Triangulasi yang digunakan dalam penelitian ini meliputi triangulasi sumber, triangulasi metode, dan triangulasi data atau analisis. Triangulasi sumber dilakukan dengan cara cross-check data dengan fakta dari narasumber. Triangulasi metode dilakukan dengan cara menggunakan beberapa metode dalam mengumpulkan data yaitu wawancara mendalam terhadap narasumber, observasi terhadap operasional chainsaw saw pada pekerjaan menebang pohon, dan observasi terhadap data sekunder. Triangulasi data atau analisis dilakukan dengan cara melakukan cek ulang jawaban yang diberikan narasumber dengan cara menanyakan kembali maksud dari narasumber untuk memastikan kebenaran jawaban.

Langkah awal adalah mengidentifikasi bahaya pada setiap aktivitas pengoperasian chainsaw pada pekerjaan menebang pohon. Identifikasi bahaya dilakukan dengan cara menarik kesimpulan dari hasil observasi dan wawancara serta dari data sekunder. Setiap bahaya dirinci risiko murninya.

Setiap risiko murni akan dinilai dengan menggunakan teknik analisis semi kuantitatif, yaitu penilaian risiko menggunakan nilai numerik, namun hasilnya sebagian besar bersifat kualitatif. Risiko dinilai dengan cara perkalian antara nilai kemungkinan kejadian (likelihood) dan tingkat keparahan dampak (severity). Matriks penilaian risiko terdapat pada tabel 1 .
Perkalian antara nilai likelihood dan nilai severity akan menunjukkan total nilai risiko. Risiko murni diklasifikasikan menjadi 3 berdasarkan tingkat risikonya, antara lain yaitu risiko rendah, risiko sedang, dan risiko tinggi. Nilai risiko dievaluasi berdasarkan tingkatnyas seperti pada Tabel 2 .

Tabel 1. Risk Assesment Matrix

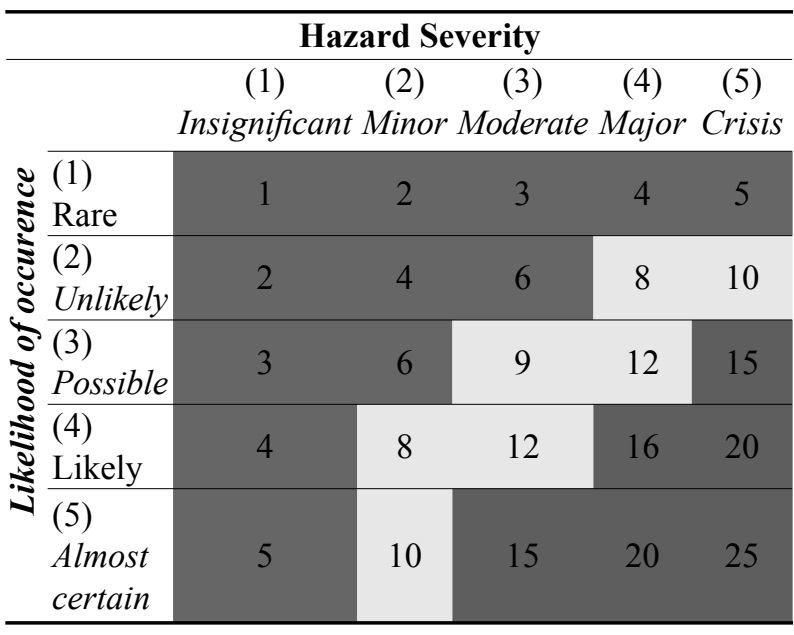

Sumber: AS/NZS 4360:1999

Tabel 2. Evaluasi Nilai Risiko

\begin{tabular}{|c|c|c|}
\hline $\begin{array}{l}\text { Nilai } \\
\text { Risiko }\end{array}$ & $\begin{array}{c}\text { Tingkat } \\
\text { Risiko }\end{array}$ & Evaluasi \\
\hline $1-6$ & $\begin{array}{l}\text { Risiko } \\
\text { Rendah }\end{array}$ & $\begin{array}{l}\text { Mungkin dapat diterima; namun } \\
\text { tetap meninjau kembali apakah } \\
\text { risiko dapat dikurangi. }\end{array}$ \\
\hline $7-12$ & $\begin{array}{l}\text { Risiko } \\
\text { Sedang }\end{array}$ & $\begin{array}{l}\text { Tugas hanya dapat dilanjutkan } \\
\text { dengan otorisasi manajemen } \\
\text { setelah berkonsultasi dengan } \\
\text { tenaga ahli dan tim penilai. Jika } \\
\text { memungkinkan tugas harus } \\
\text { didefinisikan kembali untuk } \\
\text { memperhitungkan bahaya atau } \\
\text { harus mengurangi risiko lebih } \\
\text { lanjut sebelum dimulainya tugas }\end{array}$ \\
\hline $15-25$ & $\begin{array}{l}\text { Risiko } \\
\text { Tinggi }\end{array}$ & $\begin{array}{l}\text { Tugas tidak boleh dilanjutkan, } \\
\text { harus dilakukan penerjemahan } \\
\text { ulang tugas atau melakukan } \\
\text { perhitungan pengendalian yang } \\
\text { sesuai untuk mengurangi risiko } \\
\text { sebelum dimulainya tugas }\end{array}$ \\
\hline
\end{tabular}

Sumber: $A S / N Z S$ 4360:1999

\section{HASIL}

\section{Identifikasi Bahaya}

Identifikasi bahaya dilakukan untuk dapat mengetahui bahaya yang ditimbulkan dari aktivitas 
pekerjaan menebang pohon menggunakan chainsaw, Upaya ini dimaksudkan untuk mengumpulkan, mencatat dan mengenal berbagai bahaya dan risiko di lingkungan kerja yang kemungkinan dapat menyebabkan suatu kecelakaan kerja. Identifikasi bahaya dilakukan dengan metode proaktif, yaitu mencari bahaya sebelum bahaya tersebut menimbulkan akibat atau dampak yang merugikan, dengan instrumen Job Safety Analysis (JSA) yang berisikan aktivitas dan bahaya. Pengisian JSA diperoleh dari hasil wawancara dan observasi di lapangan, bahaya di setiap aktivitas pekerjaan pengoperasian chainsaw saw pada pekerjaan menebang pohon. Teknik ini digunakan untuk melihat secara langsung setiap kegiatan penebangan serta bahaya dan risiko yang ada pada pekerjaan pengoperasian chainsaw tersebut, Metode ini juga digunakan untuk menentukan tindakan pengendalian yang tepat, sehingga bahaya yang ada dapat diantisipasi sejak awal kegiatan dimulai sampai selesai. Sehingga, dapat mengurangi risiko terjadinya kecelakaan kerja.

Aktivitas pada pekerjaan pengoperasian chainsaw diperoleh dari dokumen manual book dan dokumen tahapan pekerjaan penebangan pohon atau SOP dokumen tahapan pekerjaan pemanenan kayu hutan produksi.

Identifikasi bahaya yang dilakukan pekerjaan menebang pohon kayu hutan produksi perum perhutani KPH madiun. Pekerjaan menebang pohon dilakukan dengan menggunakan alat mekanik yaitu chainsaw. Penebangan pohon menggunakan alat tersebut dilakukan oleh seorang operator chainsaw dan dibantu oleh 1 (satu) orang asisten operator yang memandu pada saat penebangan berlangsung.

Pada proses penebangan kayu hutan produksi di Perum Perhutani KPH Madiun digunakan 1 jenis chainsaw (dikutip dari hasil Indept Interview dengan safety offficer).

Hasil data sekunder yang diperoleh peneliti dari perusahaan dan indept interview dengan safety offficer menunjukkan hasil pengukuran fisis pada areal kerja berupa suara dari chainsaw sebesar $107 \mathrm{db}$ yang sudah melebihi nilai ambang batas dan penggukuran ergonomi menunjukkan data beban berat chainsaw yang melebihi $10 \mathrm{~kg}$ dapat berisiko mempengaruhi kesehatan serta menurunkan kinerja dari proses produksi.

Hasil dari wawancara dengan operator chainsaw tentang bahaya yang ada dan risiko yang terjadi di lapangan menambah kedalaman dan detail identifikasi bahaya terhadap pekerjaan pengoperasian chainsaw di perum perhutani KPH madiun.
Semua aktivitas operator dalam mengoperasikan chainsaw terpusat di dalam hutan. Banyak bahaya yang dapat mempengaruhi keselamatan dan kesehatan operator selama mengoperasikan chainsaw di dalam hutan.

\section{Penilaian Risiko}

Penilaian risiko atau risk assessment pada potensi bahaya yang telah ditemukan dari identifikasi bahaya. Penilaian risiko adalah proses untuk mengevaluasi risiko yang muncul akibat dari suatu bahaya, dengan memperhitungkan kecukupan pengendalian yang telah dilakukan, dan menetapkan apakah risiko dapat diterima atau tidak (Ramli, 2010).

Risk Assessment (Penilaian risiko) merupakan salah satu tahap dalam risk management untuk mengevaluasi risiko yang muncul dari suatu bahaya. Penilaian risiko didasarkan pada tingkat kemungkinan (likelihood) dan tingkat keparahan dampak (saverity) yang dihasilkan dari terjadinya kecelakaan karena risiko tersebut.

Penilaian risiko yang dilakukan dalam penelitian ini dianalisis secara semi kuantitatif dengan standar dari $A S / N Z S 4360$, yaitu penilaian risiko menggunakan nilai numerik. Analisis risiko dilakukan dengan cara penghitungan hasil kali antara tingkat kemungkinan (likelihood) dan tingkat keparahan dampak (severity).

Inti dari penilaian risiko adalah mengurangi risiko menggunakan data pendukung yang digunakan sebagai pertimbangan pengambilan keputusan tentang cara pengendalian yang tepat dan cost effective (AS/NZS 4360: 1999).

Berikut adalah tahapan menentukan angka tingkat peluang (likelihood) dalam penilaian risiko (Ramli, 2010): Menentukan peluang insiden yang terjadi di tempat kerja, dapat menggunakan skala berdasarkan tingkat potensinya. Berikut ini adalah faktor yang dapat mempengaruhi peluang terjadinya sebuah insiden: berapa orang yang terpapar, durasi paparan, jumlah material atau tingkat paparan, keterampilan dan pengalaman orang yang terkena, dan berapa kali situasi terjadi.

\section{Evaluasi Risiko}

Evaluasi risiko merupakan tahapan dalam memberikan makna yang jelas pada risiko bagi manajemen untuk menentukan upaya pengendaliannya. Evaluasi risiko yang dilakukan untuk menilai apakah risiko tersebut dapat diterima atau tidak yang dikategorikan kedalam 3 kategori 
Tabel 3. Tingkat peluang (likelihood)

\begin{tabular}{cll}
\hline Tingkat & Kriteria & Penjelasan \\
\hline 1 & Rare & $\begin{array}{l}\text { Bahaya sangat kecil, bahkan } \\
\text { tidak pernah. Kecuali, } \\
\text { bertahun-tahun. }\end{array}$ \\
\hline 2 & Unlikely & $\begin{array}{l}\text { Kejadian mungkin terjadi } \\
\text { pada kondisi tertentu, tetapi } \\
\text { kecil kemungkinan. }\end{array}$ \\
\hline 3 & Moderate & $\begin{array}{l}\text { Kejadian mungkin terjadi } \\
\text { beberapa kondisi tertentu. }\end{array}$ \\
\hline 4 & Likely & $\begin{array}{l}\text { Kejadian sering terjadi atau } \\
\text { hampir pasti terjadi di semua } \\
\text { kondisi. }\end{array}$ \\
\hline 5 & Almost & $\begin{array}{l}\text { Kejadian pasti terjadi di } \\
\text { semua kondisi. }\end{array}$ \\
\hline
\end{tabular}

Sumber: $A S / N Z S 4360$
Tabel 4. Tingkat keparahan (severity)

\begin{tabular}{|c|c|c|}
\hline Tingkat & Kriteria & Penjelasan \\
\hline 1 & $\begin{array}{l}\text { Insigni- } \\
\text { ficant }\end{array}$ & $\begin{array}{l}\text { a. Non-cidera } \\
\text { b. Kerugian finansial dan material } \\
\text { sangat kecil }\end{array}$ \\
\hline 2 & Minor & $\begin{array}{l}\text { a. P3K } \\
\text { b. Kerugian finansial dan material } \\
\text { sedang }\end{array}$ \\
\hline 3 & Moderate & $\begin{array}{l}\text { a. Penanganan medis } \\
\text { b. Kerugian finansial dan } \\
\text { materialcukup besar }\end{array}$ \\
\hline 4 & Major & $\begin{array}{l}\text { a. Cacat atau hilangnya fungsi } \\
\text { anggota tubuh total } \\
\text { b. Kerugian material besar }\end{array}$ \\
\hline 5 & $\begin{array}{l}\text { Catastro- } \\
\text { phic }\end{array}$ & $\begin{array}{l}\text { a. Kematian } \\
\text { b. Kerugian material sangat besar }\end{array}$ \\
\hline
\end{tabular}

Sumber: $A S / N Z S 4360$

Tabel 5. Hasil Risk Assessment pada Pekerjaan Menebang Pohon di Perum Perhutani KPH Madiun pada Bulan Agustus Tahun 2015

\begin{tabular}{|c|c|c|c|c|c|}
\hline \multirow{2}{*}{ Komponen } & \multirow{2}{*}{ Bahaya } & \multirow{2}{*}{ Risiko } & \multicolumn{2}{|c|}{ Risk Matrix } & \multirow{2}{*}{$\begin{array}{l}\text { Tingkat } \\
\text { Risiko }\end{array}$} \\
\hline & & & Likelihood & Severity & \\
\hline \multirow[t]{18}{*}{$\begin{array}{l}\text { Menebang } \\
\text { Pohon }\end{array}$} & Kick back chainsaw & $\begin{array}{l}\text { Cedera pundak, dapat terpotongnya } \\
\text { anggota tubuh bagian atas }\end{array}$ & 4 & 4 & 16 \\
\hline & $\begin{array}{l}\text { Tertimpa ranting pohon } \\
\text { yang kering atau mati }\end{array}$ & Kepala, badan terluka & 4 & 5 & 20 \\
\hline & Terjatuh dari pijakan & Dislokasi sendi, luka berat & 3 & 3 & 9 \\
\hline & Terkena perkul & $\begin{array}{l}\text { Kaki luka (telapak kaki, punggung } \\
\text { kaki, dan betis) }\end{array}$ & 3 & 3 & 9 \\
\hline & Terkena pecahan baji & Kepala, badan terluka & 4 & 4 & 16 \\
\hline & Terkena pecahan baji & Mata terluka & 4 & 4 & 16 \\
\hline & $\begin{array}{l}\text { Terkena serpihan pohon } \\
\text { saat dipotong }\end{array}$ & Luka tergores & 3 & 2 & 6 \\
\hline & Tertusuk tunggak & $\begin{array}{l}\text { Kaki luka (telapak kaki, punggung } \\
\text { kaki, dan betis) }\end{array}$ & 3 & 4 & 12 \\
\hline & Suara chainsaw & Tuli & 4 & 3 & 12 \\
\hline & Terpapar sinar matahari & Head stroke & 4 & 3 & 12 \\
\hline & $\begin{array}{l}\text { Portur kerja yang tidak } \\
\text { sesuai }\end{array}$ & Low back pain & 3 & 3 & 9 \\
\hline & $\begin{array}{l}\text { Beban berat saat membawa } \\
\text { chainsaw }\end{array}$ & Low back pain & 3 & 3 & 9 \\
\hline & $\begin{array}{l}\text { Tempat busi motor tidak } \\
\text { sesuai standart }\end{array}$ & Tersengat listrik & 3 & 5 & 15 \\
\hline & Tergigit ular & Luka tersayat, terkena racun & 3 & 5 & 15 \\
\hline & Tanaman beracun & Gatal-gatal & 3 & 2 & 6 \\
\hline & Menghirup gas buangan & Keracunan udara & 2 & 2 & 4 \\
\hline & $\begin{array}{l}\text { Tertusuk ranting dan dahan } \\
\text { yang berserakan }\end{array}$ & Luka tersayat, luka ringan & 3 & 2 & 6 \\
\hline & $\begin{array}{l}\text { Tertimpa pohon karena } \\
\text { arah rebah yang tidak } \\
\text { sesuai }\end{array}$ & Kepala, badan terluka & 4 & 5 & 20 \\
\hline
\end{tabular}

Sumber: (Pradipta, 2015) 
yaitu risiko dapat diterima (generally acceptable), risiko dapat ditolerir (tolerable), dan risiko tidak dapat diterima (generally unacceptable), yang dikenal dengan sebutan ALARP (As Low As Reasonably Practicable). Hasil evaluasi risiko menunjukkan bahwa dari total 18 risiko yang telah dikategorikan, terdapat $39 \%$ risiko yang tidak dapat diterima, $39 \%$ risiko dapat ditolerir dan $22 \%$ risiko yang dapat diterima. Peringkat risiko ini akan menentukan proioritas pengendalian.

\section{PEMBAHASAN}

\section{Identifikasi Bahaya}

Identifikasi bahaya dilakukan dengan mengenali seluruh kondisi yang berpotensi mengakibatkan terjadinya kecelakaan. Menurut OHSAS 18001:2007, identifikasi bahaya merupakan proses untuk mengetahui suatu bahaya dan karakteristiknya.

Identifikasi bahaya berdasarkan pengamatan dan observasi serta wawancara indepth interview dengan operator chainsaw menghasilkan 18 macam bahaya yang dapat menimbulkan 18 macam risiko kecelakaan kerja. Semua bahaya tersebut bersumber pada pekerjaan menebang pohon kayu hutan produksi

Bahaya mekanis yang teridentifikasi adalah terjadi kick back pada alat penebangan chainsaw, kick back pada chainsaw adalah chainsaw yang berbalik arah akibat benturan permukaan rantai (yang berputar dengan cepat) dengan bagian ujung atas bilah gergaji dengan kayu, (buku pintar perlindungan K3 kegiatan penebangan kayu, IPB press) dapat menyebabkan risiko cedera pundak, dapat terpotongnya anggota tubuh bagian atas. Potensi bahaya tertimpa ranting pohon yang kering atau mati dapat menyebabkan risiko kepala dan badan terluka. Potensi bahaya terjatuh dari pijakan pada saat menebang dapat menyebabkan risiko dislokasi sendi dan luka berat, dikarenakan lingkungan kerja yang berada di hutan dengan tingkat kemiringannya mencapai 40 derajat serta struktur tanah yang tidak rata. Operator juga tidak memakai alat pelindung diri seperti safety shoes sehingga risiko terjadinya hal tersebut sangat tinggi. Potensi bahaya terkena perkul dan tertusuk tunggak dapat menyebabkan risiko terjadinya Kaki luka (telapak kaki, punggung kaki, dan betis). Operator juga tidak memakai alat pelindung diri seperti safety shoes sehingga risiko terjadinya hal tersebut sangat tinggi. Potensi bahaya terkena pecahan baji dapat menyebabkan risiko mata terluka pada saat menebang dan menyebabkan risiko mata terluka, operator chainsaw tidak memakai alat pelindung diri berupa safety googles pada saat menebang mengakibatkan risiko tersebut dapat terjadi. Bahaya terkena serpihan kayu pohon saat dipotong dapat menyebabkan risiko luka tergores, operator tidak melengkapi dirinya dengan alat pelindung diri seperti safety googles dan pakaian operator yang tidak sesuai membuat risiko tersebut dapat terjadi. Potensi bahaya tertusuk ranting dan dahan yang berserakan dapat menyebabkan risiko luka tersayat dan luka ringan, dikarenakan hasil pemotongan kayu pohon yang terdiri dari batang, ranting, dan dahan tidak segera diangkut, Operator juga tidak memakai alat pelindung diri seperti safety shoes sehingga risiko dapat terjadi. Potensi bahaya tertimpa pohon karena arah rebah yang tidak sesuai, tertimpa ranting pohon yang kering atau mati dan terkena pecahan baji dapa menyebabkan risiko kepala dan badan terluka, operator pada saat menebang tidak mengenakan alat pelindung diri seperti safety helmet sehingga tidak ada perlindungan untuk operator chainsaw.

Bahaya fisis yang teridentifikasi adalah terpapar oleh suara motor chainsaw yang sangat keras sampai mencapai $107 \mathrm{db}$ yang dapat menyebabkan risiko ketulian, serta dapat disebabkan karena tidak dipakainya alat pelindung diri berupa ear muf dan juga pada kenalpot alat chainsaw tidak dipasang alat peredam bunyi yang seharusnya ada pada alat tersebut. Bahaya terpapar sinar matahari dapat menyebabkan risiko head stroke, suhu panas yang berada di lingkungan kerja yang disebabkan oleh paparan sinar matahari langsung, tidak adanya pakaian pelindung diri yang digunakan juga menjadi salah satu risiko tersebut.

Bahaya ergonomi yang teridentifikasi adalah postur kerja yang tidak ergonomi (membungkuk) dan beban berat chainsaw yang harus dibawa oleh seorang operator, berat dari pada chainsaw adalah $10 \mathrm{~kg}$ dapat menyebabkan risiko low back pain.

Bahaya biologis yang teridentifikasi adalah terdapat binatang yang beracun seperti ular yang dapat menimbulkan risiko terkena racun ular dan luka tersayat, karena lingkungan kerja yang berada di dalam hutan memungkinkan adanya binatang yang beracun seperti ular yang dapat menimbulkan risiko tersebut. Bahaya tumbuhnya pohon-pohon bergetah dan daun pohon yang beracun dapat menyebabkan risiko gatal-gatal.

Bahaya listrik yang teridentifikasi adalah tidak standartnya tempat busi motor chainsaw karena tidak ditemukannya penutup pada busi motor dapat menyebabkan risiko tersengat listrik. 
Bahaya kimia yang teridentifikasi adalah terpaparnya gas buangan pada alat chainsaw yang berdampak pada udara sekitar yang tidak baik menyebabkan risiko keracunan udara.

\section{Penilaian Risiko}

Aktivitas pekerjaan menebang pohon mempunyai 18 bahaya dan dapat menimbulkan 18 risiko dari semua risiko tersebut dilakukan penilaian risiko yang nantinya dapat dikategorikan risiko tersebut.

Risiko cedera pundak dan dapat terpotongnya anggota tubuh bagian atas, diberikan skor likelihood 4 (empat) atau likely kemungkinan peristiwa kick back chainsaw itu sangat mungkin sering terjadi pada tempat kerja, untuk severity diberikan skor 4 (empat) atau major karena dapat menimbulkan cedera parah, cacat tetap, atau kematian tunggal kerugian finansial besar. Hasil perkalian likelihood atau severity menggunakan risk matrix didapatkan hasil 16 (enam belas) atau termasuk pada kategori risiko tinggi.

Risiko kepala dan badan terluka diberikan skor likelihood 4 (empat) atau likely kemungkinan peristiwa tertimpa ranting pohon yang kering atau mati itu sangat mungkin sering terjadi pada tempat kerja, untuk severity diberikan skor 5 (lima) atau Castratrophic karena berdampak pada banyak kematian dan menimbulkan kerugian sangat besar bagi perusahaan. Hasil perkalian likelihood atau severity menggunakan risk matrix didapatkan hasil 20 (dua puluh) atau termasuk pada kategori risiko tinggi.

Risiko kepala dan badan terluka diberikan skor likelihood 4 (empat) atau likely kemungkinan peristiwa terkena pecahan baji itu sangat mungkin sering terjadi pada tempat kerja, untuk severity diberikan skor 4 (empat) atau major karena dapat menimbulkan cedera parah, cacat tetap, atau kematian tunggal kerugian finansial besar. Hasil perkalian likelihood atau severity menggunakan risk matrix didapatkan hasil 16 (enam belas) atau termasuk pada kategori risiko tinggi.

Risiko dislokasi sendi dan luka berat diberikan skor likelihood 3 (tiga) atau possible kemungkinan terjadi peristiwa terjatuh dari pijakan itu mungkin terjadi pada tempat kerja, untuk severity diberikan skor 3 (tiga) atau moderate konsekuensinya dapat menimbulkan cedera berat, memerlukan perawatan medis tapi tidak menyebabkan cacat tetap, kerugian finansial sedang. Hasil perkalian likelihood atau severity menggunakan risk matrix didapatkan hasil
9 (sembilan) atau termasuk pada kategori risiko sedang.

Risiko Kaki luka (telapak kaki, punggung kaki, dan betis) diberikan skor likelihood 3 (tiga) atau possible kemungkinan terjadi peristiwa terkena perkul itu mungkin terjadi pada tempat kerja, untuk severity diberikan skor 3 (tiga) atau moderate konsekuensinya dapat menimbulkan cedera berat, memerlukan perawatan medis tapi tidak menyebabkan cacat tetap, kerugian finansial sedang. Hasil perkalian likelihood atau severity menggunakan risk matrix didapatkan hasil 9 (sembilan) atau termasuk pada kategori risiko sedang.

Risiko Kaki luka (telapak kaki, punggung kaki, dan betis) diberikan skor likelihood 3 (tiga) atau possible kemungkinan terjadi peristiwa tertusuk tunggak itu mungkin terjadi pada tempat kerja, untuk severity diberikan skor 4 (empat) atau major karena dapat menimbulkan cedera parah, cacat tetap, atau kematian tunggal kerugian finansial besar. Hasil perkalian likelihood atau severity menggunakan risk matrix didapatkan hasil 12 (dua belas) atau termasuk pada kategori risiko sedang.

Risiko mata terluka diberikan skor likelihood 4 (empat) atau likely kemungkinan peristiwa terkena pecahan baji itu sangat mungkin sering terjadi pada tempat kerja, untuk severity diberikan skor 4 (empat) atau major karena dapat menimbulkan cedera parah, cacat tetap, atau kematian tunggal kerugian finansial besar. Hasil perkalian likelihood atau severity menggunakan risk matrix didapatkan hasil 16 (enam belas) atau termasuk pada kategori risiko tinggi.

Risiko luka tergores diberikan skor likelihood 3 (tiga) atau possible kemungkinan terjadi peristiwa terkena serpihan pohon saat dipotong itu mungkin terjadi pada tempat kerja, untuk severity diberikan skor 2 (dua) atau minor karena cedera yang mungkin terjadi adalah ringan dan tidak menimbulkan kerugian finansial yang besar. Hasil perkalian likelihood atau severity menggunakan risk matrix didapatkan hasil 6 (enam) atau termasuk pada kategori risiko sedang.

Risiko luka tersayat dan luka ringan diberikan skor likelihood 3 (tiga) atau possible kemungkinan terjadi peristiwa tertusuk ranting dan dahan yang berserakan itu mungkin terjadi pada tempat kerja, untuk severity diberikan skor 2 (dua) atau minor karena cedera yang mungkin terjadi adalah ringan dan tidak menimbulkan kerugian finansial yang besar. Hasil perkalian likelihood atau severity 
menggunakan risk matrix didapatkan hasil 6 (enam) atau termasuk pada kategori risiko sedang.

Risiko patah tulang dan kematian diberikan skor likelihood 4 (empat) atau likely kemungkinan peristiwa tertimpa pohon karena arah rebah yang tidak sesuai itu sangat mungkin sering terjadi pada tempat kerja, untuk severity diberikan skor 5 (lima) atau Castratrophic karena berdampak pada banyak kematian dan menimbulkan kerugian sangat besar bagi perusahaan. Hasil perkalian likelihood atau severity menggunakan risk matrix didapatkan hasil 20 (dua puluh) atau termasuk pada kategori risiko tinggi.

Risiko tuli diberikan skor likelihood 4 (empat) atau likely kemungkinan peristiwa terpapar suara chainsaw itu sangat mungkin sering terjadi pada tempat kerja, untuk severity diberikan skor 3 (tiga) atau moderate konsekuensinya dapat menimbulkan cedera berat, memerlukan perawatan medis tapi tidak menyebabkan cacat tetap, kerugian finansial sedang. Hasil perkalian likelihood dan severity menggunakan risk matrix didapatkan hasil 12 (dua belas) atau termasuk pada kategori risiko tinggi, sedang.

Risiko headstroke diberikan skor likelihood 4 (empat) atau likely kemungkinan peristiwa terpapar sinar matahari itu sangat mungkin sering terjadi pada tempat kerja, untuk severity diberikan skor 3 (tiga) atau moderate konsekuensinya dapat menimbulkan cedera berat, memerlukan perawatan medis tapi tidak menyebabkan cacat tetap, kerugian finansial sedang. Hasil perkalian likelihood dan severity menggunakan risk matrix didapatkan hasil 12 (dua belas) atau termasuk pada kategori risiko sedang.

Risiko low back pain diberikan skor likelihood 3 (tiga) atau possible yaitu mungkin terjadi dalam semua keadaan normal karena posisi kerja yang tidak ergonomis, untuk severity diberikan skor 3 (tiga) atau moderate konsekuensinya dapat menimbulkan cedera berat, memerlukan perawatan medis tapi tidak menyebabkan cacat tetap, kerugian finansial sedang. Hasil perkalian likelihood dan severity dari bahaya low back pain menggunakan risk matrix menunjukkan hasil 9 yang masuk pada kategori risiko sedang.

Risiko low back pain diberikan skor likelihood 3 (tiga) atau possible yaitu mungkin terjadi dalam semua keadaan normal karena beban berat saat membawa chainsaw, untuk severity diberikan skor 3 (tiga) atau moderate konsekuensinya dapat menimbulkan cedera berat, memerlukan perawatan medis tapi tidak menyebabkan cacat tetap, kerugian finansial sedang. Hasil perkalian likelihood dan severity dari bahaya low back pain menggunakan risk matrix menunjukkan hasil 9 yang masuk pada kategori risiko sedang.

Risiko terkena racun ular dan luka tersayat diberikan skor likelihood 3 (tiga) atau possible karena mungkin terjadi karena lingkungan kerja yang berada di dalam hutan memungkinkan adanya binatang yang beracun seperti ular, untuk severity diberikan skor 5 (lima) atau Castratrophic karena berdampak pada banyak kematian dan menimbulkan kerugian sangat besar bagi perusahaan. Hasil perkalian likelihood atau severity menggunakan risk matrix didapatkan hasil 15 (lima belas) atau termasuk pada kategori risiko tinggi.

Risiko gatal-gatal diberikan skor likelihood 3 (tiga) atau possible kemungkinan terjadi bahaya tersebut mungkin terjadi pada tempat kerja, untuk severity diberikan skor 2 (dua) atau minor karena cedera yang mungkin terjadi adalah ringan dan tidak menimbulkan kerugian finansial yang besar. Hasil perkalian likelihood atau severity menggunakan risk matrix didapatkan hasil 6 (enam) atau termasuk pada kategori risiko sedang.

Risiko tersengat listrik diberikan skor likelihood 3 (tiga) atau possible karena mungkin terjadi karena oleh tidak standartnya tempat busi motor chainsaw, untuk severity diberikan skor 5 (lima) atau Castratrophic karena berdampak pada banyak kematian dan menimbulkan kerugian sangat besar bagi perusahaan. Hasil perkalian likelihood atau severity menggunakan risk matrix didapatkan hasil 15 (lima belas) atau termasuk pada kategori risiko tinggi.

Risiko keracunan udara, memiliki skor likelihood 2 (dua) atau unlikely karena kejadian termasuk langka terjadi pada saat perakitan chainsaw, untuk severity diberikan skor 2 (dua) atau minor karena cedera yang mungkin terjadi adalah ringan dan tidak menimbulkan kerugian finansial yang besar. Hasil perkalian likelihood dan severity menggunakan risk matrix didapatkan hasil 4 (empat) atau masuk pada kategori risiko rendah yang berarti tidak diperlukan pengendalian tambahan namun peninjauan ulang secara berkala tetap diperlukan untuk memastikan bahwa tingkat risikonya masih akurat dan tidak meningkat dengan berjalannya waktu.

\section{Evaluasi risiko}

Evaluasi risiko yang dilakukan yaitu dengan menentukan prioritas risiko berdasarkan ALARP (As Low As Reasonably Practicable) standar Australia 
10014b dalam buku Ramli (2010), pada analisa dan evaluasi risiko dapat diperoleh kesimpulan sebagai berikut:

Terdapat 4 (empat) warna hijau dengan score 1-6 artinya risiko rendah (low risk), dari proses pekerjaan menebang pohon menggunakan chainsaw di Unit Penebangan Kayu Hutan Produksi Perum Perhutani KPH Madiun Pada Bulan Agustus Tahun 2015, secara umum risiko dapat diterima (generally acceptable), akan tetapi perlu diadakan peninjauan ulang terhadap pekerjaan agar risiko lebih lanjut dapat dikurangi.

Terdapat 7 (tujuh) warna kuning dari proses pekerjaan menebang pohon menggunakan chainsaw di Unit Penebangan Kayu Hutan Produksi Perum Perhutani KPH Madiun Pada Bulan Agustus Tahun 2015 dengan score 7-14 artinya risiko sedang (medium risk). Risiko dapat ditolerir (tolerable) dan pekerjaan hanya boleh diteruskan dengan keputusan manajemen dan telah dikonsultasikan dengan tenaga ahli dan tim penilai. Bila mungkin pekerjaan harus ditetapkan ulang untuk memperhitungkan bahaya yang terlihat atau selanjutnya risiko lebih dahulu direduksi sebelum pekerjaan dimulai.

Terdapat 7 (tujuh) warna merah artinya risiko tinggi (high risk) yaitu risiko tidak dapat diterima (generally unacceptable) dengan score 15-25 dari proses pekerjaan menebang pohon menggunakan chainsaw di Unit Penebangan Kayu Hutan Produksi Perum Perhutani KPH Madiun Pada Bulan Agustus Tahun 2015 dengan peringkat risiko tersebut berdasarkan Ramli (2010), yaitu pekerjaan tidak boleh dilanjutkan, pekerjaan harus ditetapkan ulang atau dilakukan upaya pengendalian di tempat kerja untuk mengurangi risiko.

Risiko yang termasuk kedalam kategori tidak dapat diterima merupakan risiko dengan tingkat risiko tinggi. Risiko yang termasuk kedalam kategori dapat ditolerir merupakan risiko dengan tingkat risiko sedang dan risiko yang termasuk dalam kategori dapat diterima merupakan risiko dengan tingkat risiko rendah.

\section{SIMPULAN}

Berdasarkan identifikasi bahaya yang telah dilakukan dari pekerjaan penebangan pohon kayu hutan produksi dengan menggunakan chainsaw terdapat 18 bahaya yang dapat menimbulkan 18 risiko kecelakaan pada tempat kerja dengan kategori 4 risiko rendah, 7 risiko sedang, dan 7 risiko tinggi.
Risiko yang paling dominan yang didapat dari hasil risk assessment adalah risiko tinggi dan risiko sedang yang masing mempunyai jumlah 7 bahaya atau 39\% dari seluruh potensi bahaya yang ada, untuk itu pekerjaan tidak boleh dilanjutkan, pekerjaan harus ditetapkan ulang atau dilakukan upaya pengendalian di tempat kerja untuk mengurangi risiko.

\section{DAFTAR PUSTAKA}

Australian/New Zealand Standard AS/NZS 4360:1999. Risk Assesment. Standards Association of Australia.

ASEAN OSHNET Occupational Safety and Health Network (Jejaring Kerja di bidang Keselamatan dan Kesehatan Kerja antara Negara-Negara ASEAN), 2004; dapat di simak di situs web http:// www.asean-osh.net

Gani, S. 1992. Ketenagakerjaan dan Keselamatan Kerja. Fakultas Kehutanan Institut Pertanian Bogor. IPB Press, Bogor.

Matangaran, J.R. 2007. Pengetahuan tentang Chainsaw (Prinsip Kerja dan Pengoperasian). Bogor: Fakultas Kehutanan IPB.

OHSAS 18001: 2007. Occupational Health and Safety Assessment Series.

Pradipta, R. A. 2015. Risk Management Keselamatan dan Kesehatan Kerja K3 pada Unit Penebangan Kayu di Hutan Produksi (Studi pada Pekerjaan Pengopeasian Chainsaw Perum Perhutani KPH Madiun). Skripsi. Fakultas Kesehatan Masyarakat, Universitas Airlangga.

Ramli, S. 2010. Pedoman Praktis Manajemen Risiko dalam Perspektif K3 OHS Risk Management. Cetakan Pertama. Dian Rakyat. Jakarta.

Suparto, R.S. 1999. Pemanenan Kayu. IPB Press. Bogor

Strehlke, B.F. 1991. Management in Indonesia: employment, working conditions and occupational safety. Availableat.http://www.fao.org/docrep/ u 8520e/u8520e06.htm (Sitasi 13 November 2015).

Staaf, K.A.G., N.A. Wiksten. 1984. Tree Harvesting Techniques. Martinus Nijhoff/Dr.W. Junk Publishers. Dordrecht, The Netherlands.

Suhartana, S., Yuniawati. 2011. Tingkat Pemahaman Keselamatan dan Kesehatan Kerja pada Kegiatan Pemanenan Kayu Jati di KPH Cianjur.Jurnal Penelitian Hasil Hutan, Volume 29 No. 1, Halaman 46-56. 